\title{
INAPLICABILIDAD POR INCONSTITUCIONALIDAD DEL ARTÍCULO 206 DEL CÓDIGO CIVIL (TRIBUNAL CONSTITUCIONAL)
}

\author{
Comentario de Gonzalo Lepe Ruiz
}

Santiago, veintinueve de septiembre de dos mil nueve.

VISTOS:

Con fecha cuatro de marzo de dos mil nueve, ingresó al Tribunal el Oficio $\mathrm{N}^{\circ} 729$ 2009, fechado el veintiséis de febrero del mismo año, por el cual el Juez Presidente del Juzgado de Familia de Pudahuel, señor Carlo Marcelo Casaula Mezzano, expone que en la causa RIT $\mathrm{N}^{\circ} \mathrm{C}-111-2009$, seguida por investigación/reclamación de paternidad, caratulada “Muñoz con Muñoz”, se ha ordenado oficiar a esta Magistratura Constitucional para que se pronuncie sobre la inaplicabilidad del artículo 206 del Código Civil, por ser contrario a la Ley Fundamental, resolviendo, si así lo estima, la suspensión del procedimiento.

La norma impugnada por el juez requirente dispone:

"Art. 206. Si el hijo es póstumo, o si alguno de los padres fallece dentro de los ciento ochenta días siguientes al parto, la acción podrá dirigirse en contra de los herederos del padre o de la madre fallecidos, dentro del plazo de tres años, contados desde su muerte o, si el hijo es incapaz, desde que éste haya alcanzado la plena capacidad".

En la resolución de veinte de febrero del mismo año, cuya copia se acompaña, se señala que el conflicto constitucional que se pide resolver a este Tribunal, con respecto a la aplicación del artículo 206 del Código Civil en la causa sub lite, consiste en que, a juicio del juez requirente, dicho precepto legal impediría al presunto hijo de un padre que fallece con posterioridad a los 180 días siguientes al parto, demandar el reconocimiento de su filiación en contra de los herederos de ese presunto padre fallecido; efecto aquél que, según sostiene, sería contrario al derecho a la identidad que se encuentra reconocido y asegurado a toda persona en tratados internacionales vigentes y ratificados por Chile, como lo son la Convención Americana sobre Derechos Humanos (artículos 3, 5.1, y 11.1) y el Pacto Internacional de Derechos Civiles y Políticos (artículos 16 y 17.1), mismos que deben entenderse incorporados a nuestro régimen jurídico y ser respetados por el Estado y sus órganos, conforme lo establece el artículo $5^{\circ}$, inciso segundo, de la Constitución Política. Concretamente, el magistrado requirente sostiene que "la norma del artículo 206 del Código Civil, insertada en nuestra legislación en virtud de la Ley $N^{\circ} 19.585$ 
de fecha 26 de octubre de 1998, vedaria en la especie de modo absoluto al actor la posibilidad de ejercer su derecho a la identidad en cuanto lo priva de las acciones procesales idóneas para ese efecto, ya que conforme a la redacción del texto legal, lo coloca en una hipótesis diversa de las que contempla para legitimarlo activamente".

Además el juez de familia estima que la aplicación de la mencionada norma legal en esta causa en particular, produciría infracción a la garantía de igualdad ante la ley que se encuentra asegurada en el $\mathrm{N}^{\circ} 2$ del artículo 19 de la Carta Fundamental, ya que, a su entender, establecería una discriminación que no resistiría ningún test de racionalidad o proporcionalidad, entre los presuntos hijos de padres fallecidos para demandar su filiación, considerando sólo el momento del fallecimiento del presunto padre.

Precisando esta causal de inconstitucionalidad, aduce que la aplicación del artículo 206 del Código Civil, en la causa judicial ya singularizada, establecería una discriminación entre aquellos hijos cuyo presunto padre o madre falleció dentro de los 180 días siguientes al parto, a quienes les reconoce la acción de reclamación, y aquellos hijos cuyo presunto padre o madre fallece con posterioridad al transcurso de los 180 días siguientes al parto, a quienes se les priva de toda acción que les permita reclamar su filiación. Tal discriminación no encuentra, a su juicio, justificación alguna, ni siquiera en la historia fidedigna de la norma.

Para una mejor inteligencia de sus argumentos, acompaña al requerimiento copia de la tesis para optar al grado de Magíster en Derecho de Infancia, Adolescencia y Familia, titulada "¿Quiénes y bajo qué presupuestos detentan la titularidad de la acción de reclamación de la filiación en el caso que el padre o la madre a quien deba demandar ha fallecido con anterioridad a la interposición de la demanda?", presentada a la Universidad Diego Portales por la magistrado titular de ese mismo Juzgado de Familia, señora Nel Greeven Bobadilla.

Respecto de los hechos que motivan la causa sub lite, se expone que con fecha 10 de octubre de 2008, la señora María Angélica Sepúlveda le señaló a su hijo, don Felipe Gonzalo Muñoz Sepúlveda, de 24 años de edad, que su padre biológico, don Luis Arturo Muñoz Vásquez, había fallecido el día 2 de ese mes. Le indicó que ambos se habían conocido en 1982 iniciando una relación sentimental con ocasión de la cual nació Felipe Gonzalo, el 21 de noviembre de 1984. Con siete meses de embarazo, la madre se alejó del progenitor, perdiendo todo contacto. El año 2008, la señora María Angélica Sepúlveda se reencontró con el padre, acordándose la posibilidad de reconocer la paternidad, lo que no se realizó a raíz del fallecimiento de este último. El día 13 de enero de 2009, Felipe Gonzalo interpuso reclamación de filiación no matrimonial en contra de Víctor y Cecilia Muñoz Ávalos, en sus calidades de herederos de Muñoz Vásquez, padre biológico del demandante, fundando su pretensión en los artículos 179, 186 y 206 del Código Civil.

Se relata que el día 13 de febrero de 2009, don Víctor Muñoz Ávalos contesta la demanda interpuesta, señalando que "sus padres" se encontraban separados de hecho desde 1972 y, legalmente, desde el año 1982; que nunca se tuvo noticias de la existencia de este hijo y que le extraña la tardanza para ejecutar la acción de declaración de filiación. Por lo tanto, el actor carece de legitimación activa, ya que no se encuentra en ninguna 
de las hipótesis del artículo 206 del Código Civil, lo que, concordado con el artículo 317 del mismo Código, implica que el demandante no es legítimo contradictor.

Con fecha dieciocho de marzo del año en curso, la Primera Sala del Tribunal declaró admisible el requerimiento y ordenó la suspensión del procedimiento en que incide. Pasados los autos al Pleno del Tribunal, se dispuso su notificación a los órganos constitucionales interesados y a las partes del proceso sub lite, sin que se recibieran observaciones ni antecedentes de parte de ninguno de ellos.

Se ordenó traer los autos en relación y, con fecha nueve de julio de dos mil nueve, se procedió a la vista de la causa.

\section{CONSIDERANDO:}

\section{El conflicto constitucional sometido a eSte Tribunal}

PRIMERO: Que el artículo 93, inciso primero, $\mathrm{N}^{\circ} 6^{\circ}$, de la Constitución Política de la República dispone que es atribución del Tribunal Constitucional "resolver, por la mayoría de sus miembros en ejercicio, la inaplicabilidad de un precepto legal cuya aplicación en cualquier gestión que se siga ante un tribunal ordinario o especial, resulte contraria a la Constitución";

SEGUNDO: Que la misma norma constitucional expresa, en su inciso undécimo, que, en este caso, "la cuestión podrá ser planteada por cualquiera de las partes o por el juez que conoce del asunto" y agrega que "corresponderá a cualquiera de las salas del Tribunal declarar, sin ulterior recurso, la admisibilidad de la cuestión siempre que verifique la existencia de una gestión pendiente ante el tribunal ordinario o especial, que la aplicación del precepto legal impugnado pueda resultar decisivo en la resolución de un asunto, que la impugnación esté fundada razonablemente y se cumplan los demás requisitos que establezca la ley";

TERCERO: Que, como se ha indicado en la parte expositiva, el Juez de Familia de Pudahuel ha solicitado a esta Magistratura que se pronuncie acerca de la inaplicabilidad del artículo 206 del Código Civil en la causa por investigación/reclamación de paternidad, caratulada "Muñoz con Muñoz", RIT C-111-2009, sustanciada por ese tribunal, por considerar que la aplicación del referido precepto legal en ella podría vulnerar el artículo $5^{\circ}$, inciso segundo, de la Constitución, en relación con diversos tratados internacionales, y el artículo 19 No 2 de la misma Carta Fundamental;

CUARTO: Que, de acuerdo a lo expuesto por el juez requirente y a los antecedentes del proceso que acompaña, puede sostenerse que el conflicto constitucional sometido a la decisión de esta Magistratura consiste en que, de aplicarse el artículo 206 del Código Civil, a la resolución de aquél, podría verse vulnerada la obligación que pesa sobre todos los órganos del Estado de respetar y promover los derechos esenciales que emanan de la naturaleza humana, consignada en el inciso segundo del artículo $5^{\circ}$ de la 
Carta Fundamental. Entre dichos derechos se encontraría, precisamente, el derecho a la identidad personal consagrado, con diferentes términos, en varios tratados internacionales de aquellos que han sido ratificados por Chile y que se encuentran vigentes. Lo anterior, porque la redacción del precepto legal impugnado dejaría al demandante en el proceso individualizado en el considerando anterior fuera de las hipótesis admisibles para ser considerando como legitimado activo en la reclamación de paternidad que ha deducido, privándolo, en consecuencia, de una acción procesal idónea para que le sea reconocida su filiación y, por ende, su derecho a la identidad personal;

QUINTO: Que sin perjuicio de lo señalado en el considerando que precede, el conflicto constitucional planteado por el juez requirente dice relación también con la supuesta discriminación arbitraria que habría introducido el artículo 206 del Código Civil entre aquellos hijos cuyo padre o madre fallece dentro de los 180 días siguientes al parto versus aquellos hijos cuyo padre o madre fallece después de vencido ese plazo, pues los primeros sí podrían deducir la acción de reclamación de la filiación contra los herederos del padre o madre fallecido, mientras que los segundos se encontrarían privados de dicha acción, sin que exista razón válida que lo justifique;

SEXTO: Que constatado que se ha sometido al Tribunal Constitucional un conflicto de intereses de relevancia jurídica de aquellos que la Constitución le ha confiado resolver, corresponde examinar cada uno de los vicios de constitucionalidad planteados en el requerimiento;

\section{INFRACCIÓN AL ARTÍ́CULO 5º, INCISO SEGUNDO, DE LA Constitución Política}

SÉPTIMO: Que, en cuanto a la primera impugnación de constitucionalidad, el juez requirente ha sostenido que "la norma del artículo 206 del Código Civil, insertada en nuestra legislación en virtud de la Ley $N^{0} 19.585$ de fecha 26 de octubre de 1998, vedaría en la especie de modo absoluto al actor la posibilidad de ejercer su derecho a la identidad en tanto lo priva de las acciones procesales idóneas para ese efecto, ya que conforme a la redacción del texto legal, lo coloca en una hipótesis diversa de las que contempla para legitimarlo activamente".;

OCTAVO: Que, en lo que atañe al derecho a la identidad personal, el requerimiento consigna dos órdenes de argumentaciones:

a) Que diversos tratados internacionales de aquellos que Chile ha ratificado y que se encuentran vigentes, consagran este derecho. Éste es el caso de la Convención Americana de Derechos Humanos que prescribe que: "Toda persona tiene derecho a un nombre propio y a los apellidos de sus padres o al de uno de ellos. La ley reglamentará la forma de asegurar este derecho para todos, mediante nombres supuestos si fuere necesario" (artículo 18). 
El Pacto Internacional de Derechos Civiles y Políticos precisa, por su parte, que "todo niño será inscrito inmediatamente después de su nacimiento y deberá tener un nombre" (artículo 24.2).

A su turno, la Convención sobre los Derechos del Niño dispone que: "El niño será inscrito inmediatamente después de su nacimiento y tendrá derecho desde que nace a un nombre, a adquirir una nacionalidad y, en la medida de lo posible, a conocer a sus padres y a ser cuidado por ellos. Los Estados Partes velarán por la aplicación de estos derechos de conformidad con su legislación nacional y las obligaciones que hayan contraído en virtud de los instrumentos internacionales pertinentes en esta esfera (...)" (artículo 7, numerales 1 y 2).

b) Que de las referidas normas internacionales, unidas a doctrina autorizada que cita, se infiere que "la identidad queda comprendido (sic) en la categoría de 'los derechos esenciales que emanan de la naturaleza bumana' como reza el artículo $5^{\circ}$ de la Constitución Política de la República, toda vez que atañe intrínsecamente a su propia individualidad tanto personalmente como en su dimensión social, sobrepasando el ámbito inicialmente resguardado referido a los derechos del niño para entender que beneficia a toda persona en su condición de tal".;

NOVENO: Que debe reconocerse, en efecto, que los diversos instrumentos internacionales, ratificados por Chile y vigentes, que cita el juez requirente en apoyo de su argumentación, consagran el derecho a la identidad personal generando, por ende, la obligación de los órganos del Estado de respetarlos y promoverlos, en los términos aludidos en el inciso segundo del artículo $5^{\circ}$ de la Carta Fundamental.

La afirmación precedente se concilia perfectamente con el criterio sostenido por esta Magistratura en el sentido de que el derecho a la identidad personal está estrechamente ligado a la dignidad humana, en cuanto valor que, a partir de su consagración en el artículo $1^{\circ}$, inciso primero, de la Ley Suprema, constituye la piedra angular de todos los derechos fundamentales que la Ley Suprema consagra. Asimismo, que aun cuando la Constitución chilena no reconozca, en su texto, el derecho a la identidad, ello no puede constituir un obstáculo para que el juez constitucional le brinde adecuada protección, precisamente por su estrecha vinculación con la dignidad humana y porque se encuentra protegido expresamente en diversos tratados internacionales ratificados por Chile y vigentes en nuestro país (Sentencia Rol No 834, considerando 22º);

DÉCIMO: Que, en esta perspectiva, el reconocimiento del derecho a la identidad personal -en cuanto emanación de la dignidad humana- implica la posibilidad de que toda persona pueda ser ella misma y no otra, lo que se traduce en que tiene derecho a ser inscrita inmediatamente después de que nace, a tener un nombre desde dicho momento y, en la medida de lo posible, a conocer a sus padres y a ser cuidada por ellos. Si bien esta forma de entender el derecho a la identidad personal se deriva del artículo $7^{\circ}$ de la Convención sobre los Derechos del Niño, no cabe restringir su reconocimiento y protección a los menores de edad. Ello, porque el derecho a la identidad personal constituye un derecho personalísimo, inherente a toda persona, independientemente de su edad, sexo o condición social. 
La estrecha vinculación entre el derecho a la identidad personal y la dignidad humana es innegable, pues la dignidad sólo se afirma cuando la persona goza de la seguridad de conocer su origen y, sobre esa base, puede aspirar al reconocimiento social que merece. Desde este punto de vista, el derecho a la identidad personal goza de un status similar al del derecho a la nacionalidad del que una persona no puede carecer.

Las consideraciones que preceden justifican, precisamente, incluir el derecho a la identidad personal entre aquellos derechos esenciales a la naturaleza humana a que alude el artículo $5^{\circ}$, inciso segundo, de la Constitución, y que se erigen como límite de la soberanía, debiendo los órganos del Estado respetarlos y promoverlos, ya sea que estén asegurados en la propia Carta Fundamental o en tratados internacionales ratificados por Chile y que se encuentren vigentes;

DECIMOPRIMERO: Que en el conflicto constitucional planteado en la especie, se encuentra justamente comprometido el derecho a la identidad personal, pues la norma impugnada -el artículo 206 del Código Civil- se inserta dentro del párrafo "De las acciones de reclamación", ubicado en el Título VIII, referido a "Las acciones de filiación” que pretenden obtener el reconocimiento de ese estado civil, tanto matrimonial como no matrimonial. Esto es, se trata de un precepto en virtud del cual una persona puede perseguir el reconocimiento de su origen por la vía de la determinación precisa de quién fue su padre o su madre, asegurando, de esta manera, el conocimiento de su origen y, por ende, de su posición dentro de la sociedad;

DECIMOSEGUNDO: Que la regla general en materia de acciones de reclamación de la paternidad o maternidad se encuentra contenida en los artículos 204 y 205 del Código Civil, que distinguen entre filiación matrimonial y filiación no matrimonial.

El primero de esos preceptos indica que:

"La acción de reclamación de la filiación matrimonial corresponde exclusivamente al bijo, al padre o a la madre.

En el caso de los hijos, la acción deberá entablarse conjuntamente contra ambos padres.

Si la acción es ejercida por el padre o la madre, deberá el otro progenitor intervenir forzosamente en el juicio, so pena de nulidad".

El artículo 205, entretanto, establece que:

"La acción de reclamación de la filiación no matrimonial corresponde sólo al bijo contra su padre o madre, o a cualquiera de éstos cuando el bijo tenga determinada una filiación diferente, para lo cual se sujetarán a lo dispuesto en el artículo 208.

Podrá, asimismo, reclamar la filiación el representante legal del bijo incapaz, en interés de éste".;

DECIMOTERCERO: Que, en base a los artículos citados y como lo ha sostenido la doctrina especializada, la acción de reclamación del estado de hijo "es aquella que 
persigue determinar la filiación matrimonial o no matrimonial, que no se posee, por parte del hijo contra su padre o madre o ambos. O por parte de éstos contra el hijo y sus padres aparentes, para determinar su verdadero estado, dejando sin efecto el que mantiene aparentemente". (Maricruz Gómez de la Torre Vargas. "El sistema filiativo chileno”. Editorial Jurídica de Chile, Santiago, 2007, p. 89);

DECIMOCUARTO: Que, sobre la base de lo expresado, puede sostenerse que, en materia de acciones de filiación, la regla general está constituida por aquella acción que dirige el hijo contra el padre, la madre o ambos, o bien, por éstos contra el hijo y sus padres aparentes. En consecuencia, el artículo 206 del Código Civil constituye una excepción a la regla general, pues permite dirigir la acción de reclamación del estado de hijo, ya no contra el padre o madre, sino contra sus herederos cuando uno u otro han fallecido y siempre que se cumpla alguno de los siguientes supuestos: a) que el hijo sea póstumo o b) que alguno de los padres haya fallecido dentro de los ciento ochenta días siguientes al parto. En ambos casos la acción podrá deducirse dentro del plazo de tres años, contados desde su muerte, o si el hijo es incapaz, desde que éste haya alcanzado la plena capacidad;

DECIMOQUINTO: Que, ciertamente, no le corresponde a estos jueces constitucionales determinar si en la causa por investigación/reclamación de paternidad, caratulada "Muñoz con Muñoz", RIT C-111-2009, que sustancia actualmente el Juzgado de Familia de Pudahuel, y que constituye la gestión pendiente, concurren los supuestos necesarios para aplicar la regla de excepción contenida en el artículo 206 del Código Civil, pues ello es una labor que compete exclusivamente al juez del fondo.

Tampoco corresponde a esta Magistratura pronunciarse acerca de si el artículo 206 del Código Civil debe aplicarse con preferencia a la regla contenida en el artículo 317 , inciso segundo, del mismo cuerpo legal, que prescribe: "Son también legítimos contradictores los herederos del padre o madre fallecidos en contra de quienes el bijo podrá dirigir o continuar la acción y, también, los herederos del bijo fallecido cuando éstos se hagan cargo de la acción iniciada por aquel o decidan entablarla". La dilucidación de un conflicto de esta naturaleza también es propia del juez de familia que conoce de la causa sub lite.

En consecuencia, lo que en esta sede constitucional deberá decidirse es si la aplicación de la regla contemplada en el artículo 206 del Código Civil puede resultar contraria al artículo $5^{\circ}$, inciso segundo, de la Constitución, permitiendo que los órganos del Estado -el legislador y, eventualmente, el sentenciador de fondo- incumplan su deber de respetar y promover el derecho a la identidad personal en estrecho ligamen con la dignidad humana proclamada solemnemente en el artículo $1^{\circ}$, inciso primero, del Código Político. Dicho en otros términos, lo que habrá de resolverse en este primer capítulo de inconstitucionalidad es si el derecho a la identidad personal resulta lesionado por haberse aprobado por el legislador y, eventualmente, por aplicarse por el juzgador una norma que limita la posibilidad procesal de que una persona conozca su origen y, por ende, su posición dentro de la sociedad; 
DECIMOSEXTO: Que, desde el punto de vista anotado, es posible observar un contraste de criterios entre la doctrina especializada.

Por un lado, autores como Carlos Pizarro Wilson y Hernán Corral Talciani reconocen que el artículo 206 del Código Civil limita la posibilidad de que los herederos sean legitimados pasivos de las acciones de reclamación de la paternidad o maternidad, cuando uno o ambos padres han fallecido. El profesor Corral argumenta que "en el conflicto de intereses entre el bijo que busca determinar la filiación y concurrir en la herencia, la ley ha preferido los intereses de los herederos de no ser perturbados en la seguridad económica de su adquisición y en el derecho a la integridad psíquica y la vida privada de ver exbumados los restos mortales de su causante”. (Hernán Corral Talciani. “¿Puede interponerse la acción de reclamación de filiación en contra de los herederos del supuesto padre fallecido?”, en Gaceta Jurídica, No 347, mayo 2009, p. 21).

Es decir, para esta primera posición, el derecho a la identidad personal del hijo cuyo padre o madre fallece sin encontrarse dentro de los supuestos del artículo 206 del Código Civil cede, en su posibilidad de concreción, frente al derecho a la integridad psíquica de los herederos que no desean ver perturbada su vida familiar; al derecho a su privacidad, al verse compelidos a perturbar el descanso de su deudo fallecido mediante la correspondiente exhumación del cadáver, y al derecho a la propiedad sobre la herencia una vez que opera la sucesión por causa de muerte en su favor;

DECIMOSÉPTIMO: Que una segunda posición doctrinaria, representada, entre otros, por René Ramos Pazos, reconoce que la doctrina nacional, en general, se ha pronunciado por la negativa en cuanto a demandar a los herederos más allá de los supuestos que establece el artículo 206 del Código Civil. Sin embargo, precisa que a partir de un voto disidente del ex Ministro de la Corte Suprema, Domingo Kokisch, y del abogado integrante René Abeliuk, en sentencia de 2 de noviembre de 2004 ( Rol N$^{\circ}$ 2.820-3), se fue variando de opinión, en base a las siguientes razones:

a) Si bien el artículo 205 del Código Civil dice que la acción "le corresponde sólo al bijo contra su padre o madre", ello no obsta a que si ha fallecido el progenitor se pueda demandar a sus herederos, pues la disposición parte del supuesto que aquél está vivo. Si padre o madre han muerto, entra a operar el artículo 1097, según el cual los herederos representan al causante.

b) Cuando la ley quiere impedir que se demande a los herederos, lo dice expresamente, como ocurría en el antiguo artículo 271 del Código Civil, referido a la forma de acceder a la calidad de hijo natural.

c) El artículo 317, inciso segundo, del Código Civil, introducido por la ley de filiación, establece en términos muy amplios la legitimación de o en contra de los herederos.

d) Privar a los hijos de la posibilidad de demandar a los herederos no se compadece con el contexto de la ley -especialmente con los artículos 195, 198, 199 y 200 del Código Civil-, que posibilita una amplia investigación de la paternidad o maternidad y establece la imprescriptibilidad de la acción de reclamación. 
e) La excepción a la regla general que supone el artículo 206 del Código Civil no está en que sólo en ese caso pueda demandarse a los herederos, sino en que hay un plazo de tres años para hacerlo.

f) El inciso tercero del artículo $5^{\circ}$ transitorio de la Ley $\mathrm{N}^{\circ} 19.585$ dispone que: "No obstante, no podrá reclamarse de la paternidad o maternidad respecto de personas fallecidas con anterioridad a la entrada en vigencia de la presente ley". A contrario sensu, si a la fecha en que entró en vigencia dicha ley -27 de octubre de 1999- el padre o madre estaba vivo, a su muerte los herederos pueden ser demandados.

g) Uno de los principios fundamentales de la Ley $\mathrm{N}^{\circ} 19.585$ fue reconocer a toda persona el derecho a la identidad, esto es, a poder conocer sus orígenes. Para asegurar este derecho, la referida normativa asegura una amplia investigación de la paternidad y maternidad. Como se trata de un derecho humano, de acuerdo con lo dispuesto en el artículo $5^{\circ}$ de la Constitución, tiene aplicación preferente.

h) La Sala Constitucional de la Corte Suprema de Costa Rica, en fallo de 12 de marzo de 1999, anuló por inconstitucional una parte del artículo 95 del Código de la Familia, estimando dicho tribunal "que el derecho a la identidad no puede tener limitaciones procesales que lo afecten en su esencia; y por consiguiente, la acción no puede caducar, ni aun después de la muerte del progenitor". En similar sentido se habría pronunciado nuestra Corte Suprema en fallo de 21 de septiembre de 2006 (Rol No 3.249-05). (René Ramos Pazos. "Derecho de Familia”, Tomo II, sexta edición actualizada, Editorial Jurídica de Chile, Santiago, pp. 419-422).

Similares argumentos esgrime la profesora Maricruz Gómez de la Torre (Ob. cit., pp. 91 y 92);

DECIMOCTAVO: Que en el Mensaje que dio inicio al proyecto de ley modificatorio del Código Civil y otros cuerpos legales en materia de filiación ( $\left.\mathrm{N}^{\circ} 198-326\right)$-y que dio origen a la norma que se impugna en esta oportunidad-se lee que, entre los principios inspiradores de esa iniciativa, se encontraban:

a) El de la libre investigación de la paternidad y de la maternidad, que llevaba a "abrir la posibilidad al bijo de ejercer la acción de reclamación del estado filiativo en términos amplios, en contra de quien corresponda y apoyado por toda la gama de pruebas que admite la ley, (lo que) abre las puertas, definitivamente, a la búsqueda de la verdad real por sobre la verdad formal, que es la única que admite la actual legislación”, y

b) La necesidad de "equilibrar dos criterios fundamentales que suelen aparecer como contradictorios: el derecho a la búsqueda de la verdad por una parte y, por la otra, la preservación de la paz y la armonía familiar que, por cierto, podría verse violentada como consecuencia de procesos en que se formulen falsas imputaciones de paternidad". Agregaba que "el Proyecto visualiza ese peligro y recoge al respecto, la idea de un control preliminar de viabilidad de la demanda, similar al que consagra el derecho español. Este control de viabilidad constituye otro de los grandes principios que acoge la presente propuesta. Se trata de exigir un fundamento razonable a la demanda, en el sentido que el juez no admitirá aquella en 
que se ejercite una acción de filiación, si con ella no se presenta un principio de prueba de los bechos en que se funda".

El imperativo de exigir un fundamento razonable a la demanda, que quedó consagrado en el artículo 196 del Código Civil, fue derogado por la Ley N $\mathrm{N}^{\circ} 20.030$, del año 2005. No obstante ello y, como lo recordó este Tribunal en sentencia Rol No 834-07, el legislador igualmente desalienta hoy al litigante temerario cuya único propósito sea afectar la reputación del demandado en un juicio de reclamación de paternidad, a través de dos vías: 1) la condenación en costas, cuando el juez estima que no existió fundamento plausible para litigar, y b) la indemnización de perjuicios respectiva que se puede imponer a quien ejerza una acción de filiación de mala fe, o con el propósito de lesionar la honra del demandado (considerando $32^{\circ}$ );

DECIMONOVENO: Que, como puede colegirse, las diversas posiciones referidas a la aplicación del artículo 206 del Código Civil revelan una antinomia constitucional entendida como aquella situación en la que "los supuestos de hecho descritos por las dos normas se superponen conceptualmente, de forma tal que, al menos, siempre que pretendamos aplicar una de ellas nacerá el conflicto con la otra" (Luis Prieto Sanchís. El juicio de ponderación constitucional, en Miguel Carbonell (Coord.). "El principio de proporcionalidad en el Estado Constitucional”. Universidad Externado de Colombia, Bogotá, 2007, p. 103).

Así, si se sostiene que el artículo 206 del Código Civil procura proteger los derechos a la honra familiar y a la integridad psíquica de los herederos del causante impidiendo que, más allá de los supuestos restrictivos que contempla esa norma, se pueda accionar en contra de ellos para reclamar la paternidad o maternidad del causante fallecido, resultaría que su aplicación da efectivo cumplimiento a los derechos asegurados en los numerales $4^{\circ}$ y $1^{\circ}$, respectivamente, del artículo 19 de la Carta Fundamental y, por ende, la norma impugnada no resultaría contraria a la Constitución.

Por el contrario, la interpretación consignada precedentemente podría implicar que, al amparar tales derechos constitucionales, se dejara sin efecto los derechos a la identidad personal, a la integridad psíquica y a la honra del demandante en un juicio de reclamación de paternidad, asegurados, respectivamente, por el artículo $5^{\circ}$, inciso segundo, y por el artículo $19, \mathrm{~N}^{\text {os. }} 1^{\circ}$ y $4^{\circ}$, de la Constitución. Lo anterior, porque en el evento de haber fallecido el supuesto padre o madre, el afectado se vería impedido de accionar para reclamar su filiación contra los herederos de aquél o aquélla, si no se encuentra en los supuestos previstos en el artículo 206 del Código Civil;

VIGÉSIMO: Que, entonces, cabe preguntarse ¿qué solución debe propiciar el juez constitucional ante una antinomia de esta naturaleza? ¿Puede aplicarse el criterio de jerarquización de los derechos -sugerido para solucionar conflictos como el planteadocuando los que se encuentran comprometidos son, en general, equivalentes (derecho a la integridad psíquica y a la honra de la persona y de su familia) y, más aún, se encuentran en directa ligazón con la dignidad humana, valor supremo que preside toda nuestra Constitución?; 
VIGESIMOPRIMERO: Que, apelando a los criterios propios de la hermenéutica constitucional, parece necesario conciliar los derechos comprometidos en la antinomia producida en virtud de aquél que alude a la concordancia práctica y que exige que el intérprete pondere los bienes y derechos en conflicto a fin de armonizarlos y sólo en caso de no ser ello posible, dé prevalencia a uno sobre los otros, precisando claramente los requisitos o condiciones en que ello sería admisible. Se trata entonces de impedir el sacrificio total de cualquier principio, derecho o bien constitucional (Humberto Nogueira Alcalá. "Lineamientos de interpretación constitucional y del bloque constitucional de derechos”. Editorial Librotecnia, Santiago, 2006, p. 122);

VIGESIMOSEGUNDO: Que, siguiendo ese parámetro hermenéutico, debe tenerse presente que en la antinomia planteada el hijo que reclama la filiación de los herederos del padre o madre fallecido, no sólo está ejerciendo sus derechos a la integridad psíquica y a la honra, sino que -como ya se expresó- su derecho a la identidad personal. Es decir, coincide con los herederos en el propósito de ejercer eficazmente los dos primeros derechos mencionados, pero hay uno adicional -el de la identidad personal- que sólo está en juego tratándose de quien reclama la paternidad o maternidad.

Podría sostenerse, así, que una solución al conflicto planteado sería privilegiar la acción del hijo contra los herederos del supuesto padre o madre, sin restricciones como las que contempla el artículo 206 del Código Civil, porque, en el caso de éste hay un mayor número de derechos comprometidos que en el caso de los herederos.

Sin embargo, una solución de esa naturaleza, a juicio de esta Magistratura, no da plena aplicación al principio de concordancia práctica ya explicado;

VIGESIMOTERCERO: Que, más bien, habrá que intentar armonizar los derechos del supuesto hijo y de los herederos procurando que ninguno de ellos quede anulado.

Desde esa perspectiva, puede sostenerse que los derechos a la integridad psíquica y a la honra de los herederos podrían verse afectados por el solo hecho de deducirse una acción de filiación que perturbe la tranquilidad y seguridad de la familia, unido a la posibilidad de que deba autorizarse la exhumación del cadáver del supuesto padre o madre para practicar las pruebas biológicas correspondientes más allá de los supuestos restrictivos que consagra el artículo 206 del Código Civil.

Sin embargo, resulta evidente que la eventual afectación de la honra de la familia y de la tranquilidad psíquica de sus integrantes se ve mitigada si la legislación permite que el accionante de mala fe pueda recibir alguna sanción por su proceder perturbador, como ocurre con alguna de las vías mencionadas en el párrafo final del considerando decimoctavo de esta sentencia.

Además, parece importante diferenciar entre el reclamo destinado a constatar la calidad de hijo y aquél que, además, pretende consolidar los efectos patrimoniales que de ello se derivan. Estos últimos se encuentran afectos a las limitaciones contenidas en el artículo 195 del Código Civil que precisa: "La ley posibilita la investigación de la paternidad o maternidad, en la forma y con los medios previstos en los artículos que siguen. El derecho de reclamar la filiación es imprescriptible e irrenunciable. Sin embargo, sus efectos patrimoniales quedan sometidos a las reglas generales de prescripción y renuncia". (Énfasis añadido). 
Algunos autores -partidarios de defender la letra y el espíritu del artículo 206 del Código Civil- han llegado a esta misma conclusión. Así, se ha sostenido que: "De lege ferenda, estimamos que puede estudiarse una reforma para hacer primar el derecho a la identidad, pero siempre que sea este interés el que se persiga por el demandante. De esta manera, de modo semejante a lo que previó la ley, en el art. $5^{\circ}$ transitorio para los fallecidos antes de la entrada en vigor de la Ley $N^{0} 19.585$, se podría señalar que en tales casos la acción sólo tendrá los efectos de determinar la filiación pero no consecuencias o efectos patrimoniales". (Corral, Ob. cit., p. 21);

VIGESIMOCUARTO: Que, por lo tanto, una interpretación armónica del sistema de reconocimiento de la filiación existente en Chile permite concluir que los herederos de la persona cuya paternidad o maternidad se reclama pueden quedar salvaguardados, en alguna forma, en su integridad psíquica y en la honra de su familia y, también, en su derecho de propiedad generado a raíz de la sucesión por causa de muerte; en este último caso, porque la posibilidad de reclamar la herencia del supuesto padre o madre siempre estará limitada por las reglas generales de prescripción y renuncia.

Expresado en otros términos, esta forma de entender la calidad de los herederos como legitimados pasivos permanentes y, en todo evento, en las acciones de reclamación de maternidad o paternidad no conduce a la anulación total de sus derechos que podrían verse comprometidos, sino que simplemente los restringe, posibilidad que no le está vedada al legislador, siempre que no pase a llevar la esencia de los derechos respectivos ni les imponga condiciones, tributos o requisitos que impidan su libre ejercicio, conforme al numeral 26 del artículo 19 de la Constitución, lo que no acontece en el presente caso;

VIGESIMOQUINTO: Que, en el caso del hijo que, como ocurre en la especie, está reclamando el reconocimiento de su filiación, aunque no se encuentre dentro de los supuestos previstos en el artículo 206 del Código Civil a juicio del juez de la causa, se encontraría en la imposibilidad de accionar contra los herederos del supuesto padre viéndose privado absolutamente de la facultad de ejercer su derecho a la identidad personal, afectándose, además y de forma permanente, su integridad psíquica y su honra.

En efecto, si -como en el caso de autos- el supuesto padre ha fallecido después de transcurridos los ciento ochenta días siguientes al parto, el demandante quedará siempre con la interrogante abierta acerca de su origen $y$, por ende, de su verdadero nombre, que es un atributo de la personalidad. Esa hipótesis efectivamente podría darse en la causa sub lite en caso de que el juez estimase, precisamente, que el actor no se encuentra dentro de los supuestos contemplados en el precepto legal impugnado;

VIGESIMOSEXTO: Del examen de la discusión parlamentaria que dio origen a la Ley $\mathrm{N}^{\circ} 19.585$ puede inferirse que algunos legisladores visualizaron la total afectación para el derecho a la identidad personal que podría producirse en caso de establecer limitaciones para accionar contra los herederos cuando el padre, como en el caso en examen, ha fallecido fuera de los supuestos que se contemplaban en el artículo que se venía discutiendo y que pasó a ser el artículo 206 definitivo del Código Civil. Los 
senadores Carmen Frei, Juan Hamilton, Ricardo Núñez, Carlos Ominami y Anselmo Sule plantearon una indicación (la $\mathrm{N}^{\circ} 86$ ) para reemplazar el artículo que se venía discutiendo en orden a "suprimir el requisito de que, en este caso, la muerte del padre o madre haya ocurrido dentro de los ciento ochenta dias siguientes al nacimiento, de forma que la acción pueda entablarse contra los herederos sin esa limitación". (Segundo Informe de la Comisión de Constitución, Legislación, Justicia y Reglamento recaído en el proyecto de ley, en segundo trámite constitucional, que modifica el Código Civil y otros cuerpos legales en materia de filiación);

VIGESIMOSÉPTIMO: Que, en otro orden de consideraciones, el criterio de hermenéutica constitucional conocido como la regla del "efecto útil" exige propiciar interpretaciones que no priven absolutamente de efectos a los valores, principios y reglas constitucionales. Según Luchaire, "cuando una disposición es susceptible de dos sentidos, es preferible entenderla en aquel que le permite tener algún efecto antes que en el sentido con el cual no podría producir ninguno". (Citado por Nogueira, Ob. cit., p. 119).

Así, también desde este punto de vista, no corresponde acoger una interpretación que, restringiendo la posibilidad de obtener el reconocimiento de la paternidad sólo a la concurrencia de los supuestos previstos en el artículo 206 del Código Civil, pugne con el artículo $5^{\circ}$, inciso segundo, de la Constitución, dejando sin efecto el derecho a la identidad personal, en estrecho ligamen con el valor de la dignidad humana, consignado en su artículo $1^{\circ}$, inciso primero;

VIGESIMOCTAVO: Que, por las razones anotadas, este Tribunal decidirá que el artículo 206 del Código Civil, impugnado por el Juez de Familia de Pudahuel, en la causa sobre reclamación de paternidad RIT N ${ }^{\circ}$ C-111-2009, resulta contrario al artículo $5^{\circ}$, inciso segundo, de la Carta Fundamental, en relación con su artículo $1^{\circ}$, inciso primero, y así se declarará.

\section{INFRACCIÓN A LA IGUALDAD ANTE LA LEY}

VIGESIMONOVENO: Que el juez requirente también ha sostenido en estos autos que el artículo 206 del Código Civil podría importar una infracción a lo prescrito en el artículo $19 \mathrm{~N}^{\circ} 2$ de la Carta Fundamental, según el cual se asegura a todas las personas:

"2". La igualdad ante la ley. En Chile no hay persona ni grupo privilegiado. En Chile no hay esclavos y el que pise su territorio queda libre. Hombres y mujeres son iguales ante la ley.

Ni la ley ni autoridad alguna podrán establecer diferencias arbitrarias".

Específicamente sostiene que "(la) atenta lectura de la norma del artículo 206 del Código Civil arrastra a la conclusión que levanta una discriminación entre aquellos bijos cuyo presunto padre o madre falleció dentro de los ciento ochenta días siguientes al parto, a quienes les concede acción de reclamación que debe ser interpuesta dentro del plazo de tres años contados desde 
su muerte o, si el hijo es incapaz, desde que éste haya alcanzado la plena capacidad; y aquellos bijos cuyo presunto padre o madre fallece con posterioridad al transcurso de los ciento ochenta días siguientes al parto, a quienes derechamente se les priva de toda acción que les permita reclamar su filiación". Agrega que ni siquiera consultada la historia fidedigna del establecimiento del precepto legal reprochado es posible superar la existencia de una discriminación arbitraria entre personas que ocupan la misma situación de relevancia jurídica, superando el test de razonabilidad y proporcionalidad correspondiente;

TRIGÉSIMO: Que para efectos de dilucidar si, en el conflicto que se ha planteado, se produce una infracción al derecho a la igualdad ante la ley, es necesario determinar, en primer lugar, si realmente estamos frente a una discriminación o diferencia de trato entre personas que se encuentran en una situación similar para, luego, examinar si tal diferencia tiene el carácter de arbitraria importando una transgresión a la Carta Fundamental. Así, debe analizarse si tal diferencia carece de un fundamento razonable que pueda justificarla y si, además, adolece de falta de idoneidad para alcanzar la finalidad que ha tenido en vista el legislador. Este criterio ha sido reiterado por esta Magistratura, entre otras, en las sentencias roles $\mathrm{N}^{\text {os. }} 790,825,829$ y 834 ;

TRIGESIMOPRIMERO: Que al tenor de lo planteado es posible constatar, efectivamente, que el artículo 206 del Código Civil introduce una diferencia entre la misma categoría de personas, que corresponden a aquéllas que reclaman el reconocimiento de su filiación. En efecto, la norma legal reprochada permite accionar contra los herederos del supuesto padre o madre para obtener ese reconocimiento sólo en dos casos: a) si el hijo es póstumo o b) si el padre o madre fallece dentro de los 180 días siguientes al parto. En cambio, quienes también reclaman el reconocimiento de su filiación, pero no se encuentran dentro de los supuestos previstos en la norma cuestionada, carecen de acción para obtenerlo;

TRIGESIMOSEGUNDO: Que, comprobada la existencia de una desigualdad de trato o de una diferencia entre personas que se encuentran en la misma situación (persiguen el reconocimiento de su filiación), es necesario verificar si el fundamento de tal diferencia es razonable.

En este sentido y en palabras del Tribunal Constitucional español, "no toda desigualdad de trato resulta contraria al principio de igualdad, sino aquella que se funda en una diferencia de supuestos de becho injustificados de acuerdo con criterios o juicios de valor generalmente aceptados" (STC 128/1987);

TRIGESIMOTERCERO: Que, como se recordó, el Mensaje que dio origen a la Ley $\mathrm{N}^{\circ} 19.585$ comprendía, entre sus fundamentos, la necesidad de "equilibrar dos criterios fundamentales que aparecen como contradictorios. A saber, el derecho a la búsqueda de la verdad (relacionada con la libre investigación de la paternidad) por una parte y, por otra, la preservación de la paz y de la armonía familiar que, por cierto, podría verse violentada como consecuencia de procesos en que se formulen falsas imputaciones de paternidad". 
De allí que el antecedente del actual artículo 206 del Código Civil correspondía al artículo 200 de la referida iniciativa, que señalaba: "En caso de haber fallecido alguno de los padres, la acción se dirigirá en contra de sus herederos, dentro del plazo de dos años, contados desde el fallecimiento o desde el conocimiento de las pruebas en que se haya de fundar la demanda".

Durante el segundo trámite constitucional, el Primer Informe de la Comisión de Constitución, Legislación, Justicia y Reglamento del Senado recordó que el antecedente de la norma señalada precedentemente se encontraba en el antiguo artículo 272 del Código Civil, que exigía que la demanda presentada por el hijo natural fuera notificada en vida del supuesto padre o madre, de modo que los herederos de éstos -por remisión del artículo 318- sólo actuarían representándolos cuando fallecieran antes de la sentencia. El proyecto, en cambio, permitía que la acción reclamando la filiación matrimonial se dirija contra los herederos del padre o madre fallecidos.

Sin entregar mayores fundamentos, y como consta en la historia de la ley respectiva, la Comisión no compartió las ideas contenidas en el precepto que se comenta, en orden a admitir en general las demandas contra los herederos del padre o de la madre fallecidos, a la duración del plazo ni a la modalidad de cómputo del mismo. De allí que decidió conceder la acción de reclamación contra los herederos del padre o madre que haya fallecido antes del nacimiento del hijo o dentro de un determinado término siguiente al parto, que se amplió a los 180 días posteriores.

No obstante lo señalado, durante la discusión del proyecto que se comenta en la Cámara de Diputados, el señor Encina había dejado constancia de que "no hay razón alguna para establecer un límite arbitrario en el sentido de que proceda la acción siempre que el padre o la madre hayan fallecido dentro de los 180 días siguientes al parto - abí coincido con la Diputada señora Pía Guzmán-, lo que generaría un vacío legal, desde ese punto de vista, respecto de aquellos que fallezcan en un plazo posterior (las negritas son nuestras)". (Legislatura $\mathrm{N}^{0} 338$, sesión $\mathrm{N}^{\circ} 32$ ).;

TRIGESIMOCUARTO: Que en lo atingente al criterio que nos ocupa, el examen de la historia del establecimiento del artículo 206 del Código Civil revela que, lejos de apreciarse un fundamento objetivo y razonable en la limitación que dicha norma establece para reclamar de los herederos del padre o madre fallecidos el reconocimiento de la filiación, se tuvo en cuenta la regulación contenida en una norma precedente que aludía a una distinción entre tipos o categorías de hijos que el proyecto del Ejecutivo quiso precisamente superar. Por lo tanto, se consideró un criterio que ya no tenía cabida en la nueva legislación y que motivó -como se ha recordado- críticas de parte de algunos parlamentarios, precisamente por estimarse que introducía una diferencia entre aquellos cuyo padre o madre fallece antes o después de los 180 días siguientes al parto, generando, por ende, un vacío legal;

TRIGESIMOQUINTO: Que si de lo señalado se desprende la falta de razonabilidad en la diferencia de trato entre quienes demandan el reconocimiento de su filiación habiendo fallecido el padre o madre antes de los 180 días siguientes al parto, por un lado, o después de ese lapso, por otro, algo similar se puede afirmar en relación con el requisito de la idoneidad de la norma para perseguir el fin previsto por el legislador. 
En efecto, si, como se ha recordado se trataba de equilibrar la búsqueda de la verdad en materia de libre investigación de la paternidad con la necesidad de preservar la paz y la armonía familiar de los herederos violentada por falsas imputaciones de paternidad, bastaba con introducir resguardos frente a ese tipo de demandas (como la verosimilitud de las pruebas acompañadas) o con asegurar que se respondiera de la mala fe empleada, pero sin sacrificar el pleno respeto del derecho a la identidad personal, según se ha razonado en el capítulo anterior;

TRIGESIMOSEXTO: Que, así, la diferencia de trato introducida por el artículo 206 del Código Civil importa que si, como en la especie, una persona se entera de su verdadera filiación después de transcurridos 180 días de la muerte de su padre, frente a quien lo hace antes de transcurrido ese término, y como consecuencia de ello, se ve privada de poder accionar en pos del reconocimiento de la paternidad respectiva, ve afectado su derecho a la igualdad ante la ley;

TRIGESIMOSÉPTIMO: Que, en consecuencia, la aplicación del artículo 206 del Código Civil, en la causa que sustancia el Juez de Familia de Pudahuel, requirente en estos autos, resulta contraria al artículo 19 No 2 de la Constitución, y así se declarará;

Y VISTO lo prescrito en los artículos $1^{\circ}, 5^{\circ}$, inciso segundo, $19, \mathrm{~N}^{\circ} 2^{\circ}$, y 93 , inciso primero, $\mathrm{N}^{\circ} 6$, e inciso undécimo, de la Constitución Política, así como en las disposiciones pertinentes de la Ley $\mathrm{N}^{\circ}$ 17.997, Orgánica Constitucional del Tribunal Constitucional,

SE RESUELVE QUE SE ACOGE EL REQUERIMIENTO DEDUCIDO POR EL JUEZ PRESIDENTE DEL JUZGADO DE FAMILIA DE PUDAHUEL Y SE DECLARA QUE EL ARTÍCULO 206 DEL CÓDIGO CIVIL ES INAPLICABLE EN LA CAUSA RIT N C-111-2009, POR INVESTIGACIÓN/ RECLAMACIÓN DE PATERNIDAD, CARATULADA "MUÑOZ CON MUÑOZ", QUE SUSTANCIA ESE TRIBUNAL.

\section{DÉJESE SIN EFECTO LA SUSPENSIÓN DEL PROCEDIMIENTO DECRETADA A FOJAS 81.}

El Ministro señor Raúl Bertelsen Repetto previene que concurre a la decisión que declara la inaplicabilidad del artículo 206 del Código Civil, basado únicamente en los efectos contrarios a la garantía de igualdad ante la ley, reconocida en el $\mathrm{N}^{\circ} 2$ del artículo 19 de la Constitución Política, que resultaría de la aplicación del mencionado precepto legal en la causa que motivó el requerimiento de que conoce el Tribunal Constitucional.

No comparte, por consiguiente, aquella parte de la sentencia en que se estima que el precepto legal impugnado resulta también contrario en su aplicación al artículo $5^{\circ}$, inciso segundo, de la Carta Fundamental, porque entraña una infracción al deber constitucional de los órganos del Estado de respetar y promover derechos garantizados en tratados internacionales ratificados por Chile y que se encuentren vigentes, como sería en la especie el derecho a la identidad personal, reconocido en la Convención Americana sobre Derechos Humanos, en el Pacto Internacional de Derechos Civiles y Políticos y en la 
Convención sobre los Derechos del Niño. Y no comparte este razonamiento, porque sigue también en esta oportunidad el criterio que, más de una vez, ha sustentado el Tribunal Constitucional, conforme al cual aceptada la existencia de una infracción constitucional no es necesario pronunciarse sobre otras que puedan haberse producido.

Además, a juicio del Ministro previniente, no resulta formulada en forma convincente la incompatibilidad entre el artículo 206 del Código Civil con las normas de los tratados internacionales citados, puesto que de ellas no emana de modo inequívoco el derecho a la identidad personal que admite la sentencia, sino, más bien, el derecho a tener un nombre propio.

Acordada con el voto en contra de los Ministros señores Juan Colombo Campbell, Enrique Navarro Beltrán y Carlos Carmona Santander, quienes estuvieron por rechazar el requerimiento, fundados en lo siguiente:

PRIMERO. Que el Tribunal Constitucional no conoce de todo conflicto que se suscite. Sólo está facultado para conocer de ciertos conflictos constitucionales que lista el artículo 93 de la Constitución de modo taxativo. El resto de los conflictos, los conocen otros órganos jurisdiccionales.

SEGUNDO. Que los conflictos que conoce en sede de inaplicabilidad tienen en común el hecho que se produzca en ellos una vulneración de la Constitución, por violación de uno o más de sus preceptos, por una determinada aplicación de un precepto legal a una gestión pendiente. Lo que evalúa esta Magistratura en esos casos "...no es la eventual aplicación incorrecta o abusiva de dicho precepto [impugnado] que pudiere efectuar un tribunal, la que corresponderá corregir a través de los diversos recursos que contemplan las leyes de procedimiento, sino la aplicación de dicho precepto, que rectamente interpretado y entendido infringe la Carta Fundamental..." (STC rol 794, 12/06/2007). En otras palabras, si se infringe la ley o el conflicto es producto de cierta interpretación errada de la misma -lo que puede ocurrir, entre otras razones, porque se le está dando un sentido que ésta no tiene o porque la interpretación que se hace de ella es demasiado restringida y no aplica correctamente el elemento lógico de interpretación o porque la interpretación contradice lo dispuesto en un tratado internacional ratificado por Chile-. En todos aquellos casos no estamos frente a un conflicto del que esta Magistratura deba hacerse cargo. No corresponde transformar en conflictos de constitucionalidad los vacíos o las contradicciones de las normas legales si éstas pueden ser solucionadas con una debida interpretación o integración. En ese sentido, esta Magistratura ha señalado que son inadmisibles los requerimientos que van dirigidos en contra de las actuaciones del juez en lugar de dirigirse en contra de los preceptos aplicados.

TERCERO. Que, en el presente caso, hay un problema interpretativo de nivel legal, pues hay dos posiciones que se enfrentan sobre el sentido y alcance del artículo impugnado. Una tesis, que llamaremos restrictiva, sostiene que el artículo 206 sólo permite que los hijos del presunto padre o madre muerto para demandar a los herederos de éste en búsqueda del reconocimiento filiativo, lo puedan hacer únicamente en los dos 
casos que contempla: hijo póstumo y padre o madre fallecidos dentro de los ciento ochenta días siguientes al parto. La otra tesis, que llamaremos amplia, sostiene que este precepto debe mirarse como una excepción, pues hay otros preceptos del Código Civil que abren la posibilidad de demanda a otras situaciones que las contempladas en el precepto impugnado.

Los argumentos para una y otra tesis, han sido desarrollados en el voto de mayoría (considerandos $16^{\circ}$ y $17^{\circ}$ ). Por lo mismo, no volveremos sobre ellos.

CUARTO. Que para construir la inconstitucionalidad, el requerimiento opta por la tesis restrictiva. La imposibilidad de demandar de reconocimiento filiativo a posibles hijos que se encuentran en situaciones distintas a las reguladas en el artículo impugnado es lo que funda la eventual vulneración del derecho a la identidad (no se permite demandar a todos por el reconocimiento de su origen) y de la igualdad ante la ley (aquellos que se encuentren en las situaciones del artículo son privilegiados en relación al resto).

QUINTO. Que, como se observa, para construir la posible inconstitucionalidad se ha debido descartar la tesis que hace viable las posibles demandas y que elimina los reproches de infracción a la Constitución. Una vez tomada esa opción, se desarrollan los posibles conflictos entre derechos. Ello, a juicio de estos disidentes, implica, en primer lugar, tomar partido en un conflicto de nivel legal, invadiendo las atribuciones de los tribunales ordinarios y convirtiéndose en árbitro de de disputas legales. El hecho de que exista jurisprudencia de diversos tribunales, incluida la Corte Suprema, resolviendo el presente conflicto, sin necesidad de recurrir a normas constitucionales, demuestra la existencia de dicho conflicto legal.

No le corresponde a esta Magistratura sustituir al juez ordinario definiendo una interpretación legal correcta. Una intervención en ese sentido lo convierte en un juez de casación, o sea, de guardián de la correcta aplicación de la ley.

SEXTO. Que, en segundo lugar, implica contradecir el principio interpretativo conforme al cual sólo si se agotan las posibilidades de conciliar la norma cuestionada con la Carta Fundamental, cabe declarar la inconstitucionalidad. Pero si dicha posibilidad existe, tal declaración debe evitarse por estar en juego la presunción de constitucionalidad de las normas legales y la deferencia que esta Magistratura debe tener con el legislador.

SÉPTIMO. Que, en efecto, como lo señala García de Enterría, la presunción de constitucionalidad no es sólo la afirmación formal de que cualquier ley se tendrá por válida hasta que sea declarada inconstitucional, sino que implica materialmente algo más: "primero, una confianza otorgada al legislativo en la observancia y en la interpretación correcta de los principios de la Constitución; en segundo término, que una ley no puede ser declarada inconstitucional más que cuando exista 'duda razonable' sobre su contradicción con la Constitución; tercero, que cuando una ley esté redactada en términos tan amplios que puede permitir una 
interpretación constitucional habrá que presumir que, siempre que sea 'razonablemente posible', el legislador ha sobreentendido que la interpretación con la que habrá de aplicarse dicha ley es precisamente la que permitirá mantenerse dentro de los límites constitucionales" (García de Enterría, Eduardo; "La Constitución como norma y el Tribunal Constitucional"; Civitas; $3^{a}$ ed.; Madrid, 1985; p. 96.).

Tal como lo explica Patricio Zapata, "la doctrina de la "presunción de constitucionalidad" postula que, existiendo dudas respecto a la constitucionalidad de un acto de otro poder del Estado, el TCCh debe, en principio, presumir su constitucionalidad y abstenerse de anular las disposiciones sospechosas. Tal presunción se destruiría únicamente cuando la oposición entre el acto sospechoso y la Carta Fundamental fuera concluyente". (Zapata Larraín, Patricio, Justicia Constitucional. Teoría y Práctica en el Derecho Chileno y Comparado; Editorial Jurídica; Santiago, 2008; p. 243).

Esta misma Magistratura ha señalado, en relación al principio de constitucionalidad de la ley, que "...lo fundamental de este principio consiste en que se presumen válidas y legítimas las normas aprobadas por los Poderes del Estado y que sólo resulta prudente y aconsejable declarar su inconstitucionalidad cuando los sentenciadores lleguen a la íntima convicción que la pugna entre la norma en análisis y la Constitución es clara, resultando imposible armonizarla con ella. Este principio tiene muchos fundamentos, pero, por ahora, cabe solo señalar dos: la separación de Poderes y el recíproco respeto que los distintos órganos del Estado se deben entre si $y$, tratándose de leyes, lo difícil que resulta reemplazar la norma expulsada del ordenamiento jurídico por la declaración de inconstitucionalidad, por las complejidades propias del proceso de formación de la ley..." (STC rol 309, 4/08/2000). Este principio es más intenso aún en la inaplicabilidad, pues el precepto debe "resultar decisivo en la resolución de un asunto". Ello implica un juicio de utilidad o de eficacia del precepto legal objetado, pues si existen otros preceptos legales que permiten arribar a la misma conclusión que se produciría acogiendo la inaplicabilidad, la norma objetada no es decisiva.

OCTAVO. Que, en íntima conexión con el principio de presunción de constitucionalidad de la ley se encuentra el principio de la "interpretación conforme", en virtud del cual el Tribunal intenta "buscar la interpretación de las normas que permitan resolver, dentro de lo posible, su conformidad con la Constitución” (STC rol 217). Y sólo si ello no es posible, es decir, si se han agotado los esfuerzos de conciliación entre la norma objetada y la Constitución, cabe la declaración de inconstitucionalidad, pero no antes; "no cabe pronunciarse por la inconstitucionalidad de una norma si la misma admite, correctamente interpretada, una lectura conforme a la Carta Fundamental" (STC rol 1337).

NOVENO. Que ambos principios tienen plena aplicación en el presente caso, pues existe una interpretación que armoniza el texto impugnado con la Carta Fundamental. Ello, sumado a la presunción de constitucionalidad, impide a esta Magistratura declarar la inaplicabilidad por inconstitucionalidad del precepto legal impugnado, pues existe una duda más que razonable para proceder en este sentido. No es definitivo que exista una incompatibilidad indudable entre el artículo impugnado y la Carta Suprema. 
DÉCIMO. Que, en tercer lugar, tomar opción por la tesis restrictiva para construir la declaración de inconstitucionalidad, implica restringir la utilidad de la inaplicabilidad. En efecto, si se manda por esta Magistratura dejar de considerar el precepto objetado para la resolución del asunto, quedan subsistentes todas las normas que permiten construir la tesis amplia de la acción de legitimación. Por lo mismo, lo que se estaría haciendo al acoger la inaplicabilidad, es eliminar sólo un obstáculo interpretativo para que los jueces lleguen a la misma conclusión si hicieran un esfuerzo de armonización razonable.

UNDÉCIMO. Que, por otra parte, cabe considerar que el deber de respeto y promoción a los derechos esenciales que emanan de la naturaleza humana y que estén establecidos en tratados internacionales ratificados por nuestro país y vigentes, es un mandato para los “órganos del Estado". Pero dicho mandato lo deben cumplir desde sus propias atribuciones. El artículo $5^{\circ}$, inciso segundo, de la Constitución Política, no es una habilitación de potestades para que cualquier órgano del Estado, bajo el pretexto de invocar su obligación de respeto y promoción, exceda o invada la competencia de otros órganos del Estado. Por lo demás, este mandato no es sólo para el Tribunal Constitucional. Éste no tiene el monopolio de la promoción y respeto de los derechos esenciales consagrados en los tratados internacionales. En tal sentido, los jueces encargados de resolver la gestión pendiente tienen más que una orientación para buscar una salida al conflicto interpretativo que nos ocupa y que concilie los textos legales con los preceptos internacionales.

En el presente caso, a juicio de estos disidentes, puede perfectamente armonizarse ley y tratados, sin poner entre medio la Constitución.

DUODÉCIMO. Que, finalmente, no estamos en contra de la imprescriptibilidad de la acción de reclamación. Pero esa es una decisión que le corresponde tomar al legislador. El constituyente considera que es materia de ley definir cuándo y por qué plazo debe establecerse una regla de prescripción o de caducidad. Así lo ha hecho nuestro sistema en materia civil, penal, etc. No hay normas constitucionales que prohíban establecer reglas de prescripción. A esta Magistratura no le corresponde sustituir al legislador en esa materia, quien tiene más flexibilidad para moverse en los distintos ámbitos del sistema jurídico, ponderando cuando la seguridad jurídica, la consolidación de determinadas situaciones, justifica establecer una regla de prescripción o de caducidad. Como sostiene Teodoro Ribera, "al interior del marco constitucional, el legislador es libre de elegir la regulación que considere más óptima, siendo ésta una decisión propia de los órganos políticos, no sujeta a control jurisdiccional" (Ribera Neuman, Teodoro; El Tribunal Constitucional y su Aporte al Desarrollo del Derecho; Estudios Públicos 34; Otoño, 1989; p. 210).

Redactó la sentencia la Ministro señora Marisol Peña Torres, la prevención el Ministro señor Raúl Bertelsen Repetto y la disidencia, el Ministro señor Carlos Carmona Santander.

Notifíquese, regístrese y archívese.

Rol No 1.340-09. 


\section{COMENTARio}

La situación que origina el presente recurso de inaplicabilidad, cuyo requerimiento es interpuesto por el juez de familia que conocía el caso, dice relación con una demanda de reclamación de filiación entablada en contra de los herederos del supuesto padre del actor, quien falleció con posterioridad a los ciento ochenta días siguientes al parto.

La aplicación en sede judicial de una interpretación restrictiva y mayoritaria del artículo 206 Código Civil (en adelante CC) generaba un rechazo en las acciones de reclamación de filiación por lo siguiente: Se afirma que el artículo 206 CC es una excepción al régimen general de acciones de filiación consagrado en el artículo 317 CC, ya que si sostenemos que se pueden dirigir acciones en contra de los herederos, éstas serán admisibles en la medida que el demandante sea un hijo póstumo o que alguno de sus padres haya fallecido dentro de los ciento ochenta días siguientes al parto. En los demás casos no será posible.

En ambos supuestos el plazo para demandar es de tres años y se cuenta desde la muerte de alguno de los padres o si el hijo es incapaz, desde que éste alcance la plena capacidad.

Existe por otro lado una interpretación amplia del artículo 206 CC que sostiene, al igual que la tesis restringida, que efectivamente estamos en presencia de una norma excepcional, pero sólo respecto de las personas comprendidas en los supuestos que establece la disposición. La excepción consistiría entonces en que aquellas personas tienen un plazo de tres años para demandar a los herederos. En los demás casos siempre se podrá demandar siendo la acción imprescriptible.

El requerimiento indica que el artículo 206 CC establece una discriminación injustificada entre aquellos hijos cuyo presunto padre falleció dentro de los ciento ochenta días siguientes al parto, quienes pueden accionar de reclamación de filiación, y aquellos cuyo presunto padre o madre fallece con posterioridad al transcurso de los ciento ochenta días siguientes al parto, a quienes se le priva de acción. Se asume entonces que la interpretación que resulta contraria a la Constitución es la restrictiva.

La norma sería inconstitucional, en concepto del requirente, porque por un lado infringiría el derecho a la identidad consagrado en tratados internacionales, que vía artículo $5^{\circ}$ inciso segundo de la Constitución Política de la República, pasa a ser contenido material de la misma y que el tribunal vincula directamente con la dignidad de la persona humana consagrada en las bases de la institucionalidad.

Por otro lado se vulnera la garantía consagrada en el artículo $19 \mathrm{~N}^{\circ} 2$ de la Constitución, ya que la disposición en comento es arbitraria debido a que, sin razón alguna que la justifique, establece una diferencia entre los hijos cuyos presuntos padres fallecen dentro de los ciento ochenta días siguientes al parto y aquellos cuyos padres fallecen con posterioridad a dicho período. Estos últimos carecerían de la posibilidad de accionar y de conocer la verdad biológica a través de la acción de reclamación de filiación.

El tribunal constitucional se detiene en el análisis de las dos supuestas contravenciones ya explicitadas, comenzando por determinar si el derecho a la identidad se ve lesionado por la eventual aplicación de una norma que limita la posibilidad procesal de que una 
persona conozca su origen. A continuación expone cuál es la discusión que en doctrina se ha generado al respecto y explica que la aplicación de la llamada tesis restringida, cuya constitucionalidad se cuestiona, encuentra su fundamento en la protección de la familia y su honra, privacidad y propiedad sobre la herencia que prevalecería sobre el derecho a la identidad.

En seguida expone que la tesis amplia interpreta el artículo 206 del CC al amparo del derecho a la identidad, entendiendo que la disposición en comento se aplica sólo a las personas que se enmarcan en los supuestos previstos, siendo en todos los demás casos la acción de filiación imprescriptible y susceptible de dirigirse en contra de los herederos.

Ambas tesis constituyen manifestaciones de principios constitucionales diversos y que en el caso concreto se tornan incompatibles, revelándose de esta forma una antinomia constitucional.

En este punto la intención del Tribunal Constitucional es resolver el asunto sometido a su conocimiento buscando evitar un sacrificio total de cualquiera de los bienes constitucionales involucrados.

La solución adoptada hace prevalecer la tesis amplia, respetando los derechos y principios amparados por la tesis restringida, ya que el ejercicio del derecho a la identidad mediante la acción de reclamación de filiación por una persona que no se enmarca en los supuestos comprendidos en el artículo 206 CC, hecha fuera de los plazos generales de prescripción, no tendría ninguna incidencia respecto del derecho de propiedad de los herederos sobre la herencia del presunto padre.

En consecuencia, no se vulnera el derecho de propiedad de los herederos del presunto padre fallecido, que son demandados por el presunto hijo, cuyo posible padre fallece con posterioridad a los 180 días siguientes al parto, y el derecho a la identidad de éste no se ve vulnerado al declarar inaplicable por inconstitucionalidad el precepto en cuestión.

En concepto del Tribunal Constitucional el derecho a la identidad se traduciría en la posibilidad procesal de conocer el propio origen sin que necesariamente eso genere consecuencias patrimoniales respecto de los herederos del presunto padre fallecido, ya que esto se regiría por las reglas generales de prescripción.

Me interesa detenerme en la supuesta contradicción que se generaría entre el artículo 206 del CC y la garantía del artículo 19 N 2 de la Constitución Política de la República.

En concepto del recurrente, se configura una discriminación arbitraria entre aquellos hijos cuyo presunto padre o madre fallece dentro de los ciento ochenta días siguientes al parto y aquellos hijos cuyo presunto padre o madre falleció con posterioridad a los ciento ochenta días siguientes al parto, a quienes derechamente se les priva de toda acción.

El Tribunal Constitucional entiende que efectivamente existe una diferencia de trato, sin un fundamento que lo justifique, entre los hijos incluidos en los supuestos del artículo 206 del CC y aquellos excluidos de los mismos.

Comprobada la existencia de una desigualdad de trato entre personas que se encuentran en la misma situación, esto es, personas que persiguen el reconocimiento de su filiación, resta determinar si dicha discriminación es razonable. 
La búsqueda de la supuesta arbitrariedad de la disposición en entredicho se basa exclusivamente en el análisis de la historia de la disposición impugnada, concluyéndose que no existió ningún fundamento razonable para establecer la limitación que conlleva la aplicación del artículo 206 del Código Civil. Por tanto, estaríamos frente a una disposición legal arbitraria, que trata de forma discriminatoria a personas que buscan el establecimiento de su filiación.

Estimamos acertada la resolución del Tribunal en orden a determinar que la norma impugnada resulta inaplicable por inconstitucionalidad al entrar en contradicción con el derecho a la identidad en conexión con la dignidad y con el derecho a la igualdad. Sin embargo, no compartimos del todo la argumentación esgrimida, ya que nos parece insuficiente la sola utilización de la historia de la ley para funda la arbitrariedad.

En este sentido, debe agregarse que el Tribunal Constitucional opta por sostener que la única interpretación posible del artículo 206 del Código Civil es la denominada tesis restringida y que ésta es la que resulta inaplicable por inconstitucionalidad respecto del caso concreto.

Surge así la interrogante respecto de si la tesis amplia es constitucional. Uno podría tender a creer que la respuesta es la afirmativa, ya que pareciera ser más congruente con los principios afectados por la interpretación restrictiva de la disposición en comento.

Sin embargo, la tesis amplia no anula la inconstitucionalidad implícita del artículo en cuestión, ya que su aplicación en el caso del hijo póstumo o aquél cuyos padres presuntos fallecen dentro de los ciento ochenta días siguientes al parto, resulta con mayor razón injustificada. No existe ningún fundamento plausible para sostener que estos hijos tengan un plazo de tres años para demandar de reclamación de filiación y en cambio quienes no se enmarcan en ninguno de los supuestos del artículo 206 C.C. no tendrían plazo para accionar, toda vez que la acción de reclamación de filiación es imprescriptible.

Cualquiera de las interpretaciones posibles del artículo 206 del C.C. resultan contrarias al principio de igualdad ante la ley. Por ende, sin dejar de considerar incompleto el análisis que realiza el Tribunal Constitucional, ya que olvida que la interpretación amplia también puede resultar inconstitucional respecto de la garantía del artículo 19 $\mathrm{N}^{\circ} 2$ de la Carta Fundamental, nos parece acertada la declaración de inaplicabilidad al caso concreto.

En consecuencia, haría bien el Tribunal Constitucional en el futuro en declarar inconstitucional el precepto en cuestión. 
